\title{
Awareness, attitudes, need and demand on replacement of missing teeth among a group of partially dentate patients attending a University Dental Hospital
}

\author{
Rasika Manori Jayasinghe ${ }^{1 *}$, Janana Perera ${ }^{1}$, Vajira Jayasinghe ${ }^{1}$, Indika P. Thilakumara', Sumudu Rasnayaka', \\ Muhammad Hanafi Muhammad Shiraz', Indra Ranabahu and Sanjeewa Kularatna ${ }^{2}$
}

\begin{abstract}
Objective: Our objective was to assess awareness, attitudes, need and demand on replacement of missing teeth according to edentulous space, age, gender, ethnicity, educational level and socio-economical status of the patient.

Results: $76.2 \%$ of the study group was opined that the missing teeth should be replaced by prosthetic means. Majority were keen in getting them replaced mainly for the comfort in mastication. Although 77.9 and $32.9 \%$ were aware of the removable prostheses and implants respectively, only $25.2 \%$ knew about tooth supported bridges as an option of replacement of missing teeth. Participants' awareness on tooth and implant supported prostheses is at a higher level. Participants' opinion on need of regular dental visit was statistically significant when gender, ethnicity and education level were considered. The highest demand for replacement of missing teeth was observed in Kennedy class I and II situations in both upper and lower arches. Demand for fixed prostheses was significantly highest in Kennedy class II in upper and lower arches. In conclusion, although removable prosthodontic options are known to most of the patients, their awareness on tooth and implant supported prostheses is also at a higher level. The highest demand for replacement of missing teeth is by patients with Kennedy class I and II situations whereas Kennedy class II being the category with highest demand for fixed prostheses. We recommend that the location of missing teeth to be considered as a priority when educating patients on the most appropriate prosthetic treatment options. Dentists' involvement in educating patients on prosthetic options needs to be improved.
\end{abstract}

Keywords: Awareness, Need, Demand, Prosthodontic options, Partially dentate

\section{Introduction}

Prosthodontic treatment depends on a variety of factors. The traditional approach resulted in a fairly uniform treatment option based on the fact that the missing teeth should always be replaced [1]. With the advancements and knowledge in dentistry and improvement in oral health with declining edentulousness in many countries, a higher number of people tend to keep more teeth until later in life [2]. However, of late, patient requirements

\footnotetext{
*Correspondence: manoripathiraja@yahoo.com; manorija@pdn.ac.lk 1 Department of Prosthetic Dentistry, Faculty of Dental Sciences, University of Peradeniya, Peradeniya, Sri Lanka

Full list of author information is available at the end of the article
}

such as esthetics and functional comfort are considered more important when attempting to replace missing teeth [3-5]. Although several prosthodontic options for the replacement of missing teeth are available, some researchers have highlighted that the acceptability of these options depend on the patient's education, economy, cultural background as well as the age [6].

The methods discussed for evaluating the need for prosthetic management of partially dentate patients include the patients' demand for treatment and the objective oral status of the patients [7]. Being the only institution in the country which is involved in both undergraduate and postgraduate dental education with 
an attached teaching hospital, the findings provide an accurate picture of the patients seeking treatment from a tertiary care dental hospital. The findings of this study will help to identify the level of awareness, attitudes and demand with regard to prosthodontic treatment options in partially dentate patients as the treatment options available in the government and private sector have also increased in the country. We also attempted to identify if there is a difference between the demand (patient's perspective) and the need (the clinician's perspective). Moreover, it was expected that this will also help prevent both under and overtreatment for a given patient.

\section{Main text}

The main objective of the study was to assess the awareness, attitudes, need and demand for the replacement of missing teeth made by the participants. We also attempted to assess those four factors (awareness, attitudes, need and demand for replacement of missing teeth) specifically according to variables such as the location of the edentulous space, age, gender, ethnicity, educational level and the socio-economical status of the participant.

This cross-sectional study sample was selected from the screening clinic conducted every morning on weekdays at the Dental Hospital, Peradeniya during the years 2015 and 2016. An information sheet regarding this study was provided to all patients in their preferred language and informed written consent was obtained prior to the study.

Being a partially dentate patient and above 18 years of age were considered as the inclusion Criteria. Mentally retarded/disabled or physically handicapped patients and those from dental-related professions/occupations (dental surgeons, dental surgeons' assistants, dental technical officers and dental students) and edentulous patients were excluded from the study sample.

Following the formula, $\mathrm{N}=\mathrm{z}^{2} \mathrm{p}(1-\mathrm{p}) / \mathrm{e}^{2}$ and considering the fact that the population proportion for partially dentate patients (p) was not known, the safest choice was to use p as $0.5(\mathrm{p}=0.5)$ for the calculation of the minimum sample size of 384 in this study.

All participants (425) were subjected to an interview and a pre tested and validated questionnaire in Sinhala and Tamil languages was administered. Demographic information was recorded by the subjects. The questionnaire (printed) consisted of open ended questions related to the knowledge, attitude, and awareness of the treatment options available for tooth replacement and the justification for selecting one option over another. All questionnaires were anonymous.

A clinical examination was carried out using a mouth mirror and a probe. Each patient was examined by two separate examiners who were specialists in prosthetic dentistry/senior house officers in the Department of Prosthetic Dentistry under the supervision of a specialist in prosthetic dentistry to avoid inter examiner variability. Every tenth patient was examined twice to minimize intra-examiner variability. The house officers were trained by specialists and specialists were also available in the clinic to address any problem regarding examination, diagnosis and available treatment options. The examination was used to evaluate the need for treatment and to select the suitable prosthetic treatment option for each patient following WHO basic methods and according to the Kennedy classification of each arch. The treatment options considered here were removable partial dentures, fixed tooth supported prostheses or implant supported removable/fixed prostheses.

Responses to all questions were collected and analyzed statistically using SPSS 17.0. The results were analyzed using logistic regression by considering age, gender, ethnicity, educational level and monthly income as independent variables. Ethical Clearance was sought from the Ethics review committee, Faculty of Dental Sciences, University of Peradeniya. (ERC/FDS/UOP/I/2015/18).

The mean age of the sample was 44.38 years and twothirds of the respondents were females. Almost all participants (99.5\%) were aware that they had missing tooth/ teeth. Although their awareness on their partially dentate status correlated significantly to their level of education, it was non significant when gender was considered. (Table 1).

When participants' attitude towards the replacement of missing teeth was assessed, $76.2 \%$ were in favor of having missing teeth replaced (Table 2). However, the results were statistically non significant according to the variables we assessed. When questioned regarding the need of replacement, 101 out of 425 stated that there is no need of replacing lost teeth. Out of the remaining respondents who had a positive attitude towards the replacement of missing teeth (324), the majority claimed that the main aim of their replacement was the improvement of the masticatory ability. The highest percentage of the sample with a negative attitude towards tooth replacement was of the opinion that they did not need the replacement and the second highest reason was financial constraints (Table 3). Most of the participants (58.1\%) felt that the replacement of both anterior and posterior teeth is equally valuable, whereas $26.6 \%$ thought that the replacement of anterior teeth is more important (Table 4). The results were statistically significant when monthly income was considered. $(\mathrm{p}=0.013$ ).

When the participants were questioned regarding their plan towards the replacement of missing teeth, $68.7 \%$ displayed their preference to do so. Although $77.9 \%$ of the 
Table 1 Patients' awareness of the partially dentate status according to the level of education

\begin{tabular}{|c|c|c|c|c|c|}
\hline Characteristic & Number & Percentage & Number & Percentage & Significance \\
\hline Do you have any missing tooth/teeth? & No & $(n=2)$ & Yes & $(n=423)$ & \\
\hline \multicolumn{6}{|l|}{ Education level } \\
\hline Primary education & 1 & $50.0 \%$ & 25 & $5.9 \%$ & \\
\hline Up to grade 8 & 0 & $0.0 \%$ & 38 & $9.0 \%$ & \\
\hline Ordinary level $(\mathrm{O} / \mathrm{L})$ & 0 & $0.0 \%$ & 173 & $40.9 \%$ & $p=0.022$ \\
\hline Advanced level and above (A/L) & 0 & $0.0 \%$ & 147 & $34.8 \%$ & \\
\hline
\end{tabular}

Table 2 Attitude towards the replacement of missing teeth in relation to age, gender, ethnicity, educational levels and the socio economic levels

\begin{tabular}{|c|c|c|c|c|c|c|}
\hline Do you think you need replacement when tooth/teeth are lost? & No & $(n=101)(\%)$ & Yes & $(n=324)(\%)$ & p value & $95 \% \mathrm{Cl}$ \\
\hline \multicolumn{7}{|l|}{ Age category (years) } \\
\hline $16-20$ & 3 & 3.0 & 11 & 3.4 & \multirow[t]{4}{*}{$p=0.251$} & \multirow[t]{4}{*}{-0.001 to -0.005} \\
\hline $21-40$ & 44 & 43.6 & 111 & 34.4 & & \\
\hline $41-60$ & 41 & 40.6 & 167 & 51.7 & & \\
\hline $61-80$ & 13 & 12.9 & 34 & 10.5 & & \\
\hline \multicolumn{7}{|l|}{ Gender } \\
\hline Male & 35 & 34.7 & 118 & 36.4 & \multirow[t]{2}{*}{$p=0.946$} & \multirow[t]{2}{*}{-0.089 to -0.083} \\
\hline Female & 66 & 65.3 & 206 & 63.6 & & \\
\hline \multicolumn{6}{|l|}{ Ethnicity } & \multirow[t]{4}{*}{0.049 to 0.102} \\
\hline Sinhala & 93 & 92.1 & 291 & 89.8 & $p=0.493$ & \\
\hline Tamil & 1 & 1.0 & 8 & 2.5 & & \\
\hline Muslim & 7 & 6.9 & 25 & 7.7 & & \\
\hline \multicolumn{7}{|l|}{ Education level } \\
\hline Primary education & 10 & 9.9 & 16 & 4.9 & \multirow[t]{5}{*}{$p=0.807$} & \multirow[t]{5}{*}{-0.041 to -0.053} \\
\hline Up to Grade 8 & 7 & 6.9 & 31 & 9.6 & & \\
\hline $\mathrm{O} / \mathrm{L}$ & 41 & 40.6 & 132 & 40.7 & & \\
\hline$A / L$ & 33 & 32.7 & 114 & 35.2 & & \\
\hline Tertiary education & 10 & 9.9 & 31 & 9.6 & & \\
\hline \multicolumn{7}{|l|}{ Monthly income } \\
\hline$<10,000 /=$ Rs & 18 & 17.8 & 38 & 11.7 & \multirow[t]{5}{*}{$p=0.101$} & \multirow[t]{5}{*}{-0.006 to -0.068} \\
\hline $10,000 /=-20,000 /=R s$ & 23 & 22.8 & 75 & 23.1 & & \\
\hline $20,000 /=-30,000 /=\mathrm{Rs}$ & 31 & 30.7 & 93 & 28.7 & & \\
\hline $30,000 /=-40,000 /=R s$ & 17 & 16.8 & 64 & 19.8 & & \\
\hline$>40,000 /=$ Rs & 12 & 11.9 & 54 & 16.7 & & \\
\hline
\end{tabular}

Table 3 Participants reasons for not trying to replace missing teeth

\begin{tabular}{ll}
\hline $\begin{array}{l}\text { Reason-for no need of replacement when tooth/ } \\
\text { teeth is lost }\end{array}$ & Number (total 101) \\
\hline Financial & 16 \\
Did not feel it is needed & 68 \\
No time & 3 \\
Do not know about treatment options & 7 \\
Many reasons & 7
\end{tabular}

$24 \%$ of the participants were not keen in getting missing teeth replaced. The majority felt that they did not feel the need for the replacement and financial constraints also played a role in making the decision
Table 4 The comparative importance of the type of teeth to be replaced according to participants' attitude

\begin{tabular}{lll}
\hline Independent variable & p value & $\mathbf{9 5 \%} \mathbf{C l}$ \\
\hline Age & 0.695 & -0.006 to 0.009 \\
Gender & 0.831 & -0.224 to 0.180 \\
Ethnicity & 0.864 & -0.193 to -0.162 \\
Education level & 0.485 & -0.149 to 0.071 \\
Monthly income & 0.013 & 0.024 to 0.198 \\
\hline
\end{tabular}

The majority of the patients were of the opinion that it is important to replace both anterior and posterior missing teeth

Results were statistically significant when monthly income was considered 
participants knew about removable prostheses for the replacement of missing teeth, only 25.2 and $32.9 \%$ knew about the tooth supported and implant supported prostheses respectively (Tables $5,6,7$ ). The awareness on tooth supported fixed prostheses was statistically significant when age and educational level were considered.

The participants' awareness of regular dental visits was also assessed according to variables such as gender, ethnicity and educational level and the results revealed that it is statistically significant when gender, ethnicity and the educational levels were considered. (Table 8).

When the demand for the replacement of missing teeth was analyzed according to the position of the edentulous region in upper arch and lower arch, the results revealed that participants with Kennedy class I and II have the highest demand and this demand level was statistically significant. (Tables 9, 10) The demand for fixed prostheses was highest in Kennedy class II in upper and lower arches and the results were statistically significant. All Kennedy class IV patients were interested in fixed prostheses as the method of replacement.

\section{Limitations}

The patients' attitudes and demand towards the replacement of missing teeth might be different from the clinicians' assessment. Although prosthodontists consider factors such as the preservation of natural teeth and the maintenance of periodontal health as priority, patients

Table 5 Participants' awareness of different types of prostheses used to replace missing teeth

\begin{tabular}{lll}
\hline $\begin{array}{l}\text { Awareness on type of pros- } \\
\text { theses }\end{array}$ & Number & Percentage of population \\
\hline Removable prostheses & 331 & 77.9 \\
Tooth supported bridges & 107 & 25.2 \\
Implant supported prostheses & 140 & 32.9
\end{tabular}

About $78 \%$ of the participants were aware of removable prostheses as a mode of replacement of missing teeth. However, awareness of tooth supported fixed prostheses was less than implant-supported prostheses

Table 6 Participants' awareness on tooth supported fixed prostheses according to different variables

\begin{tabular}{lll}
\hline Independent variable & p value & $\mathbf{9 5 \%} \mathbf{C l}$ \\
\hline Age & 0.030 & -0.000 to 0.007 \\
Gender & 0.874 & -0.093 to 0.079 \\
Ethnicity & 0.635 & -0.057 to 0.094 \\
Education level & 0.024 & 0.007 to 0.101 \\
Monthly income & 0.056 & 0.000 to 0.073 \\
\hline
\end{tabular}

Participants' awareness on tooth supported bridges was statistically significant when age and educational level were considered
Table 7 Participants' demand when they were educated on different types of prostheses available

\begin{tabular}{|c|c|c|}
\hline $\begin{array}{l}\text { Demand for different pros- } \\
\text { theses }\end{array}$ & Number & Percentage of participants \\
\hline No prosthesis & 44 & 10.4 \\
\hline Removable prosthesis & 117 & 27.5 \\
\hline $\begin{array}{l}\text { Tooth supported fixed pros- } \\
\text { thesis }\end{array}$ & 72 & 16.9 \\
\hline $\begin{array}{l}\text { Implant supported fixed } \\
\text { prosthesis }\end{array}$ & 135 & 31.8 \\
\hline $\begin{array}{l}\text { Tooth/implant supported fixed } \\
\text { prosthesis }\end{array}$ & 57 & 13.4 \\
\hline
\end{tabular}

Once the knowledge on different prosthodontic options was provided, more patients requested tooth and implant-supported prostheses than removable ones. Surprisingly, 10\% did not demand any type of replacement

tend to prioritize comfort in mastication and improvement of esthetics. Therefore, it is vital to investigate patients' awareness, need and demand on prosthodontic treatment options. To the best of our knowledge, ours could be the first Sri Lankan study which assessed those variables on prosthodontic options.

Our finding that $99.5 \%$ of the respondents in the sample were aware of their partially dentate status, corresponded with other reports which have shown a high level of awareness (95.93\%). However, some studies have found a slightly significant influence of gender, which was not revealed in our study [8]. The majority of our patients were of the opinion that it is more important to replace anterior teeth and this finding is consistent with the previous studies [7].

When the participants' attitude towards the replacement of missing teeth was assessed, $76.2 \%$ of the sample showed positive attitudes, and this value is almost double the value reported by Reddy et al. [8] in Saudi Arabia in 2016. However, both studies failed to identify any statistically significant difference when attitude was assessed against the gender and the educational level of the participants. Most of the participants with negative attitudes had responded that they didn't feel that it is required to get the missing teeth replaced and the second most frequent reason given for the negative attitude was financial constraints. However, an Indian study identified financial factors as the main barrier in the decision for the replacement of missing teeth [9].

Out of 425 participants, 32\% was aware of implants as a mode of replacement. This finding corresponds to reports by previous authors [10] and the percentage we reported is higher compared to multiple studies in the Asian population $[8,11]$. This disparity could be attributed to the higher standards of health and education in the country compared to the neighbouring countries in the region. 
Table 8 Participants' awareness of the need for regular dental visits

\begin{tabular}{|c|c|c|c|c|c|c|}
\hline Do you think that a regular dental visit is needed for everybody? & No & $(n=37)(\%)$ & Yes & $(n=386)$ & p value & $95 \% \mathrm{Cl}$ \\
\hline \multicolumn{7}{|l|}{ Age category (years) } \\
\hline $16-20$ & 2 & 5.4 & 12 & 3.1 & & \\
\hline $21-40$ & 11 & 29.7 & 144 & 37.4 & & \\
\hline $41-60$ & 16 & 43.2 & 191 & 49.6 & $p=0.473$ & -0.003 to 0.001 \\
\hline $61-80$ & 8 & 21.6 & 38 & 9.9 & & \\
\hline \multicolumn{7}{|l|}{ Gender } \\
\hline Male & 21 & 56.8 & 131 & 33.9 & $p=0.009$ & 0.018 to 0.131 \\
\hline Female & 16 & 43.2 & 255 & 66.1 & & \\
\hline \multicolumn{7}{|l|}{ Ethnicity } \\
\hline Sinhala & 37 & 100.0 & 346 & 89.6 & & \\
\hline Tamil & 0 & 0.0 & 9 & 2.3 & & \\
\hline Muslim & 0 & 0.0 & 31 & 8.0 & $p=0.033$ & 0.004 to 0.104 \\
\hline \multicolumn{7}{|l|}{ Education level } \\
\hline Primary education & 3 & 8.1 & 23 & 6.0 & & \\
\hline Up to grade 8 & 9 & 24.3 & 29 & 7.5 & & \\
\hline $\mathrm{O} / \mathrm{L}$ & 16 & 43.2 & 156 & 40.4 & $p=0.025$ & 0.004 to 0.066 \\
\hline $\mathrm{A} / \mathrm{L}$ & 7 & 18.9 & 139 & 36.0 & & \\
\hline Tertiary education & 2 & 5.4 & 39 & 10.1 & & \\
\hline \multicolumn{7}{|l|}{ Monthly income } \\
\hline$<10,000 /=$ Rs & 8 & 21.6 & 48 & 12.4 & & \\
\hline $10,000 /=-20,000 /=R s$ & 7 & 18.9 & 90 & 23.3 & & \\
\hline $20,000 /=-30,000 /=\mathrm{Rs}$ & 13 & 35.1 & 111 & 28.8 & $p=0.702$ & -0.020 to 0.029 \\
\hline $30,000 /=-40,000 /=\mathrm{Rs}$ & 4 & 10.8 & 77 & 19.9 & & \\
\hline$>40,000 /=\mathrm{Rs}$ & & & & & & \\
\hline
\end{tabular}

Females were more aware of the need for regular dental visits by all individuals and the results were statistically significant

Participants of Sinhala nationality and with higher levels of education were more aware of the fact and the results were statistically significant

Table 9 The demand for the replacement of missing teeth according to the position of saddle in upper arch

\begin{tabular}{lcccccc}
\hline $\begin{array}{l}\text { Upper arch Ken- } \\
\text { nedy }\end{array}$ & None & $\begin{array}{l}\text { RPD (removable } \\
\text { partial dentures) }\end{array}$ & $\begin{array}{l}\text { TS (tooth sup- } \\
\text { ported) bridges }\end{array}$ & $\begin{array}{l}\text { Implants } \\
\text { TS bridges }\end{array}$ & $\begin{array}{l}\text { Percentage } \\
\text { and implants } \\
\text { requested fixed } \\
\text { prosthesis }\end{array}$ \\
\hline Cl (Class I) & 0 & 22 & 3 & $\begin{array}{l}\text { Percentage } \\
\text { requested } \\
\text { replacement }\end{array}$ \\
CII (Class II) & 6 & 16 & 14 & 14 & 37 \\
CIII (Class III) & 32 & 61 & 37 & 2 & 9 & 62 \\
CIV (Class IV) & 0 & 2 & 1 & 1 & 0 & 34 \\
\hline
\end{tabular}

Individuals of Maxillary Kennedy class I, II and IV were more interested in getting missing teeth replaced than class III individuals. A higher number of class II and IV individuals were keener on fixed options for replacing missing teeth than the other two classes

Table 10 The demand for the replacement of missing teeth according to the position of saddle in lower arch

\begin{tabular}{lrrrrrrr}
\hline Lower arch Kennedy & None & RPD & TS bridges & Implants & TS bridges and implants & $\begin{array}{l}\text { Percentage requested } \\
\text { fixed prosthesis }\end{array}$ & $\begin{array}{l}\text { Percentage requested } \\
\text { replacement }\end{array}$ \\
\hline Cl & 6 & 36 & 8 & 12 & 8 & 40 & 91 \\
CII & 7 & 28 & 13 & 28 & 12 & 66 & 23 \\
CIII & 27 & 45 & 40 & 6 & 5 & 100 & 71 \\
CIV & 0 & 0 & 1 & 1 & 0 & 100 \\
\hline
\end{tabular}

Individuals of Mandibular Kennedy class I, II and IV were more favorable towards the replacement of missing teeth than class III individuals. All class IV participants were interested in fixed prostheses as the option of replacement 
Moreover, we observed a very high participants' preference towards fixed prostheses supported by implants or teeth $(62 \%)$.The report of the study by Al-Quran et al. in [11] also confirms our results as only $34 \%$ preferred removable prostheses as an option. However, a similar study in Saudi Arabia highlighted that around 50\% of the sample were keen on removable partial dentures while $25 \%$ preferred tooth supported fixed prostheses, and surprisingly, none opted for implants [8]. The difference in our outcome could be explained with the higher literacy level in the country as our results were positively associated with participants' educational level and due to the use of newer mass media by the general public.

Our study claims that patients' demand for fixed prostheses is at a higher level when patients were educated on the issue and that dentists have a duty to spend time on educating patients regarding available prosthetic options. This claim is supported by the fact that most of the patients (about 34\%) highlighted that their source of information on prosthodontic options was friends or relatives. However, a study by Mukatash et al. [7] carried out in Jordan found that the major source of information for patients is dentists. Both studies reveal that mass media does not play a significant role in the education on prosthodontic aspects of dental health.

The statistically significant highest demand for fixed prostheses in Kennedy class II in upper and lower arch could be due to difficulty in mastication (which participants identified as the most important reason for replacing missing teeth) and discomfort with free end saddle removable prostheses. The fact that Kennedy class I and II have the highest overall demand for prosthetic replacement of missing teeth confirms that patients' concern for the improvement of mastication plays an important role in this high demand. The assessment of demand for different types of prostheses according to the location of the edentulous space is important in order to identify the most appropriate type of prosthesis for the patients attending dental clinics.

We consider the fact that more than $90 \%$ of the participants were aware that regular dental visits are required in order to maintain optimum oral and dental health of an individual to be a positive factor.

In conclusion, the majority of the patients were keen on getting missing teeth replaced mainly for comfortable mastication. While the removable prosthodontic options are known to most of the patients, their awareness on tooth and implant supported prostheses is also at a higher level. The highest demand for the replacement of missing teeth was made by patients with Kennedy class I and II situations while Kennedy class II was the category with the highest demand for fixed prostheses.
We recommend that the location of missing teeth be considered as a priority when educating patients on the most appropriate prosthetic treatment options. Dentists' involvement in educating patients on prosthetic options needs to be improved.

\section{Abbreviations}

O/L: ordinary level; A/L: advanced level; RPD: removable partial dentures; TS: tooth supported; Cl: class I; CII: class II; CIII: class III; CIV: class IV.

\section{Authors' contributions}

$J P, R M J, M H M S, I R, S R$ participated in the data collection. JP was the major contributor in developing the questionnaire. SK analysed, interpreted the data and corrected the manuscript. IT, VJ contributed in writing the project proposal, developing questionnaire, reading manuscript and final approval. $\mathrm{RMJ}$ was the writer and corresponding author of the manuscript. All authors read and approved the final manuscript.

\section{Author details}

${ }^{1}$ Department of Prosthetic Dentistry, Faculty of Dental Sciences, University of Peradeniya, Peradeniya, Sri Lanka. ${ }^{2}$ Australian Centre for Health Services Innovation, School of Public Health and Social Work, Queensland University of Technology, Brisbane City, Australia.

\section{Acknowledgements}

Authors would like to acknowledge the clinical support provided by the nonacademic staff at the screening clinic, Faculty of Dental Sciences and English language editing support by Dr. PM Manuratne, Senior Lecturer, Department of English, University of Kelaniya.

\section{Competing interests}

The authors declare that they have no competing interests.

\section{Availability of data and materials}

The datasets generated and/or analyzed during the current study are available from the corresponding author on reasonable request.

\section{Consent for publication}

Not applicable.

\section{Ethics approval and consent to participate}

Ethical approval was obtained from Ethics and Review Committee, Faculty of Dental Sciences, University of Peradeniya. (ERC/FDS/UOP/I/2015/18) Written informed consent was obtained from the patients.

Funding

There is no source of funding.

\section{Publisher's Note}

Springer Nature remains neutral with regard to jurisdictional claims in published maps and institutional affiliations.

Received: 9 March 2017 Accepted: 21 July 2017

Published online: 27 July 2017

\section{References}

1. Zarb GA, Bergman B, Clayton JA, Mocky HF. Prosthodontic treatment for partially edentulous patients. Maryland Heights: Mosby; 1978. p. 56-62.

2. Carlsson GE, Omar R. Trends in prosthodontics. Med Princ Pract. 2006;15(3):167-79.

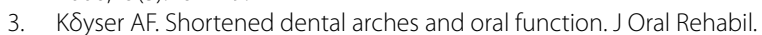
1981;8:457-62. 
4. Witter DJ, Van Elteren P, KSyser AF, Van Rossun GM. The effect of removable partial dentures on the oral function in shortened dental arches. J Oral Rehabil. 1989;16:27-33.

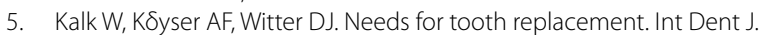
1993:43:41-9.

6. Davenport JC, Basker RM, Heath JR, Ralph JP, Glantz PO. British Dent J. 2000;89:364-68

7. Mukatash GN, Al-Rousan M, Al-Sakarna B. Needs and demands of prosthetic treatment among two groups of individuals. Indian J Dent Res. 2010;21(4):564-7.

8. Reddy RN, Elamin El, Vempalli S, Fuad AI Sanabani F. Perception and awareness of prosthodontic rehabilitation among Jazan population in the Southern Region of Saudi Arabia. Glob J Med Res. 2016;16(1):1-8.
9. Raj N, Reddy N, Japatti S, Thomas M, Uthappa R. Knowledge, attitudes towards prosthodontics rehabilitation and utilization of dental services among Songadh and Amargadh Population. J Dent Med Med Sci. 2014;3(1):1-6.

10. Suprakash B, Ahammed ARY, Thareja A, Kandaswamy R, Kumar N, Bhondwe S. Knowledge and attitude of patients toward dental implants as an option for replacement of missing teeth. J Contemp Dent Pract. 2013;14(1):115-8.

11. Al-Quran FA, Al-Ghalayini RF, Al-Zu'bi BN. Single-tooth replace-ment: factors affecting different prosthetic treatment modalities. BMC Oral Health. 2011;11:34. doi:10.1186/1472-6831-11-34.

\section{Submit your next manuscript to BioMed Central and we will help you at every step:}

- We accept pre-submission inquiries

- Our selector tool helps you to find the most relevant journal

- We provide round the clock customer support

- Convenient online submission

- Thorough peer review

- Inclusion in PubMed and all major indexing services

- Maximum visibility for your research

Submit your manuscript at www.biomedcentral com/submit 